\title{
AOR
}

Selected Papers of \#AolR2021:

The 22nd Annual Conference of the

Association of Internet Researchers

Virtual Event / 13-16 Oct 2021

\section{THE CASE ACT: IMPLICATIONS FOR INTERNET STUDIES RESEARCH}

\author{
Aram Sinnreich \\ American University \\ Patricia Aufderheide \\ American University
}

Copyright policy is inextricably entangled with the work of academic researchers on Internet culture. This paper examines a new U.S. law, the CASE Act, which creates a new venue for resolving copyright disputes for up to $\$ 30,000$. We discuss the implications of such a venue for U.S.-based internet studies research.

\section{The CASE Act and Fair Use}

Fair use is the right under U.S. law to reuse copyrighted material without licensing it or getting permission. It has become ever more valuable to creators, consumers, and scholars, as copyright monopolies have gotten longer, covered more material, and as copyright has become default upon creation. Fair use permits scholars to quote copyrighted work in their publications; to use it in experimental studies; to search databases of material for patterns; and to create multimedia e-books (Aufderheide \& Jaszi, 2018).

Interpretation of fair use has been increasingly consistent since the publication of a groundbreaking 1990 article by judge Pierre Leval (Leval 1990). Large publishers, however, have spent the internet era attempting to expand copyright protection to discourage and punish copying. Although all large media companies routinely employ fair use, they also discourage its use by other actors, and even conduct misinformation campaigns (Gillespie 2009). For years, they heavily promoted the CASE Act (for Copyright Alternative in Small-Claims Enforcement) (Authors Guild, 2019), and for years it was batted down by copyright-flexibility advocates (Electronic Frontier Foundation, 2018). In December 2020, it was quietly slipped into must-pass legislation (Electronic Frontier Foundation, 2020).

Independent creators face problems under existing copyright law if their work gets used unfairly and without permission. The chances and sizes of damage awards are too small to make a costly federal lawsuit worthwhile, discouraging enforcement. This is a 
bigger problem for creative professionals than it is for scholars (though it happens to scholars, too). The CASE Act claims to rectify this problem.

The CASE Act proposes a new venue to bring claims of copyright infringement. Instead the courts, it creates an extrajudicial tribunal at the Copyright Office. Throughout 202122 , the Copyright Office will work out specifics and logistics. We already know that the process will be available for claims up to $\$ 30,000$ (half the annual income of the average American household). For claims up to $\$ 5,000$, the process will be summary judgment (no redress). The process will be an administrative one. The decision-makers would probably be Copyright Office lawyers. A defendant can refuse to go to this nonjudicial venue, and run the risk of facing a federal lawsuit.

\section{Scholar as Defendant and Plaintiff}

Does this address copyright problems that internet scholars might have? We considered first the scholar as a potential defendant-the most likely scenario. We fielded a survey to 135 U.S.-based legal and internet scholars at all professional levels asking them how much liability they would undertake if they felt they were within their fair use rights and felt comfortable in their understanding of the law.

Results clearly show that nearly half of respondents $(42.2 \%)$ are unwilling to take on any financial risk with fair use, while most of the rest (44.4\%) are only comfortable with a risk level below $\$ 10,000$. The difference between $\$ 30,000$ (the CASE Act maximum) and $\$ 150,000$ (the maximum trial award) is functionally nothing, with $2.2 \%$ of respondents selecting values in these range.

Even among scholars who say they are confident or somewhat confident employing fair use (a figure that should be higher, creating a knowledge gap in the field [Sinnreich \& Aufderheide, 2015]), the risk tolerance is still low, with $38.8 \%$ saying they won't take any risk, and another $44.9 \%$ selecting risk levels below $\$ 10,000$.

Does the CASE Act provide opportunities for scholars as plaintiffs? This is extremely unlikely, because of the clause allowing defendants to opt out of the venue. The threat of a federal lawsuit against anyone infringing on academics' work is vanishingly small, since the costs of litigating would be overwhelming.

Thus, for scholars, the effect of the CASE Act is further intimidation in use of copyrighted material. Legal scholars expect that the major publishers, including music, movies, photography and text publishing, will seize upon the opportunity. The CASE Act also creates unprecedented opportunity for copyright trolls.

Drawing from previous research, we also argue that actual legal and paralegal actions, such as threats on legal letterhead, are only the tip of the intimidation iceberg. The internalization of exaggerated risk assessment is prevalent both among scholars (Sinnreich and Aufderheide 2015) and in other fields (Aufderheide and Sinnreich 2015, Aufderheide and Jaszi 2018). The CASE Act creates further opportunities to exaggerate that hypothetical risk. 


\section{Policy and Action Opportunities}

Scholars have several points of entry to the CASE Act as policy. First, they can participate in the Copyright Office process, which will be public. Large publishers will vociferously participate. It will be important to document how important fair use is to scholarly practice, and to show that typically universities do not carry legal responsibility for their scholars' own work. Our survey research documents the level of intimidation of even what the Copyright Office (and large publishers) regard as "small" claims.

Second, scholars can document the uses to which the CASE Act is put, and the effects-personal, cultural, scholarly. We anticipate that the new venue will be used in many areas of interest to internet scholars, e.g. memes, TikTok videos, and remix culture.

Third, scholars can act as public intellectuals, to educate the public, and particularly the creator public, about the implications of a process that operates extrajudicially to further tilt the legal playing field away from the creator and toward large publishers.

Fourth, they can educate themselves, their colleagues, students, institutions, and gatekeepers regarding the low risk of competently-exercised fair use, as delineated for instance in the International Communication Association's Code of Best Practices in Fair Use for Copyright Research, available at cmsimpact.org/ica.

\section{Conclusion}

Scholars need to be policy actors as well as researchers in the copyright arena. Copyright's biggest issues touch immediately on internet studies research. Researchbased advocacy must go hand in hand with empirical research.

\section{REFERENCES}

Aufderheide, P. and P. Jaszi (2018). Reclaiming fair use: how to put balance back in copyright. Chicago ; London, The University of Chicago Press.

Authors Guild. (2019, July 9.) Please support small claims (CASE Act). New York: Authors Guild. Retrived from https://www.authorsguild.org/industry-advocacy/please-support-small-copyright-claimscase-act/

Aufderheide, P. and A. Sinnreich (2015). "Documentarians, fair use, and free expression: changes in copyright attitudes and actions with access to best practices." Information, Communication \& Society: 1-10.

Electronic Frontier Foundation. (2018, April 23). Letter opposing the CASE Act. San Francisco: EFF. Retrieved from https://www.eff.org/document/letter-opposing-case-act

Electronic Frontier Foundation. (2020, Dec. 22). The CASE Act is just the beginning of the next copyright battle. San Francisco: EFF. Retrieved from 
https://www.eff.org/deeplinks/2020/12/case-act-hidden-coronavirus-relief-bill-justbeginning-next-copyright-battle

Gillespie, T. (2009). "Characterizing copyright in the classroom: The cultural work of antipiracy campaigns." Communication, Culture \& Critique 2(3): 274-318.

Leval, P. N. (1990). "Toward A Fair Use Standard." Harvard Law Review 103: 11051136.

Meyer, R. (2015). After 10 Years, Google Books Is Legal. The Atlantic.

Sinnreich, A. and P. Aufderheide (2015). "Communication Scholars and Fair Use: The Case for Discipline-Wide Education and Institutional Reform." International Journal of Communication 9: 818-828. 